\title{
Faculty Governance And Outcomes Assessment: Compatible Or Combustible?
}

James L. DeBoy, Lincoln University of Pennsylvania, USA

Sally B. Monsilovich, Lincoln University of Pennsylvania, USA

Joanne R. DeBoy, Lincoln University of Pennsylvania, USA

\begin{abstract}
This paper identifies the various factors driving the outcomes assessment movement, contrasts the old paradigm with the model now espoused by regional accreditors, discusses the six-step process of student outcomes assessment, emphasizes faculty ownership of the process to prevent administrative usurpation, and proposes specific strategies to enhance faculty empowerment.
\end{abstract}

Keywords: Outcomes Assessment; Faculty Governance; Teaching Effectiveness; Professional Responsibility

\section{INTRODUCTION}

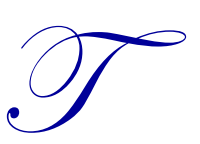

he academy is under attack as attested by legislative assault on collective bargaining, media hostility regarding tenure, proliferation of adjunct hires from 33 percent of teaching loads in 1975 to 72 percent in 2011, draconian reductions in state aid, and administrative raids on faculty e-mail accounts culminating in the corporatization of higher education (Nelson, 2011). Proponents of the corporate model argue that the aforementioned "reforms" are justified based upon the widespread dissatisfaction with higher education's cost-value efficacy (Arum \& Roksa, 2010). Clearly, escalating costs for a college education have flummoxed many of academe's constituents: students, parents, legislators, and other policymakers. When tuition surges 130 percent over the last 20 years (Bernstein, 2011), people notice and demand redress. Other factors related to financial concerns have created a vociferous public outcry about higher education in recent years. The banking/mortgage crisis, coupled with the impending automobile industry bankruptcy and a national unemployment rate of 10 percent, frightened investors and reduced state treasuries (less spending $=$ less taxes collected). These events led to a climate of "tight money" -- an era dubbed the "Great Recession" (2008present). A common query heard on many campuses - "What exactly are students (and taxpayers) receiving for those six figure baccalaureate degrees?" - must be addressed. The recent interest of the federal government in "credit hours" and "integrity issues" associated with distance education underscores the public's heightened expectations of the university's responsible use of decreasing fiscal resources (CHEA, 2010).

This paper will address how and why quality student assessment practices can enhance faculty governance and ultimately serve as a viable countermand to recent harangues lodged against higher education. It is our belief that the academy's ability to make change far outweighs its proclivity to be changed; it is that mindset that guides this paper.

\section{Rationale}

It has been argued that there are as many as three distinct curricula on most college campuses: 1) the curriculum contained in the course syllabus, 2) the curriculum that the instructor delivers in the classroom/lab/online, and 3) the curriculum with which the student enrollee exits the class at the end of the semester. Assessment of student learning is designed to align these curricula into a common, transparent, objective measure of student outcomes.

A fairly common reaction among faculty to the student assessment movement has been one of disinterest captured in the retort "Faculty have always measured and evaluated - we award grades". Historically, students 
amassing some 120 credits were awarded degrees; the measuring stick was largely completing a prescribed number of classes (curriculum $=$ "to run a course") with a minimum passing grade (C; 2.0/4.0 GPA). However, today's measuring stick now focuses upon student competency, skill, performance outcomes and not merely specific courses navigated.

The old paradigm consisted of faculty teaching their discipline to students, e.g., "I teach CHEMISTRY to students" whereby the direct object is the course itself. This model often casts the instructor (and one's discipline) as rigid, constant, and stringent. The course (content and instructional methods) is established as an immutable entity to which students must conform ...or else. Such thinking assigns faculty as gate-keepers of their discipline while learning that course content is the sole responsibility of the student. Unfortunately, this scenario has sometimes led to professors teaching the same content the same way for decades with the same (disappointing) results. If anything, these academicians have been consistent; i.e., rigid, constant and stringent.

Over the years we have heard the all-too-familiar professorial lament, "But I am a scholar - that is sufficient in and of itself!" - perhaps... if one worked solely in research or in a think tank (Suskie, 2009). The overwhelming majority of faculty work in an institution of higher learning where we are expected to teach and where students are expected to learn/master knowledge content, skills, and competencies. Teaching faculty are appointed to their respective departments to advance both their chosen discipline (by adding to its knowledge base via research, publications, projects, presentations, and partnerships) and the students with whom we interface in the classroom. If we succeed in the first endeavor but fail in the second, our initial success becomes moot if our successors cannot gain from the new-and-improved knowledge base.

The new paradigm of assessment calls for a dual responsibility for learning whereby both student and instructor collaborate to forge a learning-centered relationship. In effect, "faculty teach STUDENTS chemistry " the direct object shifts to students in this model. A common criticism to the student-focused approach equates it with social promotion whereby higher education devolves to lower; i.e., mass/crass education. Most assuredly, the new model can be misinterpreted when students correspond tuition costs with final grades awarded - If the customer/enrollee pays $\$ 1,000 /$ credit, s/he should receive a grade of $\mathrm{C}$, but when tuition costs $\$ 2,000 /$ credit, then $\mathrm{s} /$ he should receive at least a B... the more we pay, the higher grade (return) we must receive. No, not quite. Yet, policy-makers are demanding something other than status quo. That "something else" is student mastery of learning outcomes. Corporate folks' buzz word "accountability" coincides with academicians' preferred term "professional responsibility". Despite the nomenclature difference, both concepts require universities/professors to verify that graduates meet performance goals (Huffman, Adamopoulos, Murdock, Cole, \& McDermid, 2011). The penultimate evidence of teaching success will be students mastering expected outcomes.

\section{OUTCOMES ASSESSMENT PROCESS}

The first step in the assessment process necessitates the identification of student learner outcomes (SLOs) objective, measurable statements that represent the knowledge content, skills and competencies comprising any discipline. These SLOs constitute the profile or desired outcome of the learning experience, whether it be a particular lesson, unit, or program objective. These SLOs, in their totality, embody the "educated product"; i.e., those students who have demonstrated mastery. Selecting and developing these SLOs must fall under the auspices of faculty if shared governance is to be viable. As experts in their fields of study, faculty will articulate those SLOs deemed important to their discipline.

The second step in this six-stage process is the affordance of opportunities for students to master the targeted SLOs. Such interventions embrace a plethora of learning experiences/instructional methodologies lectures, discussions, readings, lab reports, papers, projects, simulations, research, theses, oral defenses, debates, and field work/practica. To increase the likelihood that students will master the content knowledge, skills or competencies, faculty must present a sufficient number of experiences that directly relate to the particular SLO.

Step 3 involves gathering of student work (actual outcomes). This collection of actual outcomes is the measurement phase; it will provide evidence of what students can or cannot do with regard to the SLOs. The most common tools will include tests and rubrics (evaluative and checklist, to name but two types). 
Perhaps, the most challenging of the six steps is Step 4 - analysis whereby actual outcomes (data collected in measurement phase) are compared to desired outcomes (SLOs). When discrepancies occur between the two, then the SLO has not been met. This component of the process need not be laborious when writing the analysis report. However, for some academicians with an orientation toward the verbose, this step can derail the assessment effort. A brief description of the measurement tool, what precisely it identified (actual outcomes), followed by what should have been gathered, will constitute the analysis section. In short, step 4 determines the extent to which SLOs have been mastered, if at all; and if/when students do not demonstrate mastery, faculty are then faced with four possible courses of action - Step 5:

- $\quad$ Revise or abandon the SLO

- $\quad$ Modify instructional strategies

- $\quad$ Modify the curricular content (offer more or less)

- Modify the measurement tool (used to collect the actual outcomes)

This fifth step in the assessment process places the burden of change squarely on the shoulders of faculty. When students fail to learn; i.e., master the SLO, faculty must change... something. To teach the same way that yields the same ineffectual results is shirking one's professional responsibility. While we cannot guarantee student mastery, we are obligated to make changes designed to improve the likelihood of student success. While we cannot merely award passing grades, we are duty-bound to reconfigure our curricular goals, adjust our delivery for instruction, and fine-tune our measurement tools while maintaining professional standards of our fields of study. Most assuredly, student tuition dollars do warrant Steps 1-5, but mastering those SLOs that comprise the educational program remains the sine qua non of the student. While it is legalistically true that 'failure to learn' does not bespeak failure to teach, it is our opinion that 'failure to change' on the part of the professorate is tantamount to neglect of duty. That having been said, the process of student mastery is concurrently augmented with instructors' changing goals, methods, content, and measurement instruments when the student mastering process flounders.

When these five steps are faculty-driven, faculty autonomy is enhanced. When faculty develop the SLOs, determine the learning experiences that directly bear on the SLOs, select the measurement tools, analyze the data (compare actual outcomes to desired outcomes), and implement changes based upon said analyses, then faculty governance is assured. If faculty ignore or minimize their role in the assessment enterprise and/or non-academicians usurp this faculty function, then "... we will find ourselves teaching a curriculum determined by others... that reflects the interests of (corporate) others..." (Smith, 2011, p. 216)

Step 6 is the marketing campaign that showcases best practices of student assessment. Quality assessment of student learning can generate scholarship - paper presentations at professional conferences, journal articles, and on-campus forums/workshops are familiar vehicles to share successful assessment practices. Furthermore, best practice artifacts (rubrics, value-added effects) are welcome additions to faculty promotion-tenure portfolios.

\section{CONCLUSION}

As an institution, higher education has not fared very well in trumpeting its own horn. The professoriate has historically dismissed efforts to "sell itself" to the public. The reasons for such deliberate inaction are multitudinous - time-consuming, too little gain, unnecessary, inglorious, and sheer arrogance, to name but a few. However, as stated in the opening sentence of this paper, the academy itself is seriously challenged by a skeptical public - Is the college degree all that it has been made up to be? Rising tuition costs, increasing student debt, and uncertain employment prospects for graduates only exacerbate the general public's concern. If public trust is to be captured, faculty must demystify academe. When faculty fully participate in the six-step assessment process, transparency and accountability unfold. People outside the education establishment will gain a clearer picture of what we do, why we do it, and how well we do it. We owe our constituents and our profession nothing less. 


\section{AUTHOR INFORMATION}

James L. DeBoy earned a Ph.D. in Human Development (with minor concentrations in Special Education and History of Education) at the University of Delaware. He was appointed to the Lincoln University faculty in 1975 and achieved academic rank of Professor in 2000. As Chair of the HPER Department since 1989, he has served on virtually all major academic committees, assumed the lead role in assessment of student learning outcomes for 20 years, served key roles in the university's re-accreditation process for three decades, and successfully taught more than 10 different health-focused courses over a 35 year career in higher education. Dr. DeBoy has presented papers at regional, national, and international conferences on such diverse topics as motor development, alcohol abuse prevention, student learner outcomes in health sciences, human cognition/metacognition, and obesity testing across the curriculum. E-mail: Luhper1111@aol.com (Corresponding author)

Sally Monsilovich earned an Ed.D. in Health Education at Temple University, Pennsylvania. She was appointed to the Lincoln University faculty in 1990 and currently holds the Associate Professor rank. She has served on many major university committees, successfully taught 10 courses in the Health Science Department over the last 20 years, and has taught/led myriad health fitness programs in the community. Her current areas of research include: nutrition, fitness, and body image in relation to obesity.

Joanne R. DeBoy earned an Ed.D. in Psychology of Reading at Temple University, Pennsylvania. She was first appointed to the Lincoln University faculty in 1980 where she served the Education Department of eight years when she re-entered public school administration and served as principal of a large public elementary school for 18 years. In 2005, she returned to Lincoln University as Associate Professor and Chair of the Education Department. Her areas of expertise include: school administration, reading and literacy instruction.

\section{REFERENCES}

1. Arum, R., \& Roksa, J. (2010). Academically adrift. University of Chicago Press.

2. Bernstein, S. (2011). Trends in college pricing. The College Board, 1-32.

3. CHEA. (2010). US department of education publishes proposed regulations addressing program integrity and student aid programs. federal update. CHEA, 11, 1-5.

4. Huffman, L., Adamopoulos, A., Murdock, G., Cole, A., \& McDermid, R. (2011). Strategies to motivate students for program assessment. Educational Assessment, 16, 90-103.

5. Hutchings, P. (2010). Opening doors to faculty involvement in assessment. National Institute for Learning Outcomes Assessment - Occasional Paper \# 4.

6. Nelson, C. (2011). Opening remarks AAUP national conference. Symposium Conducted at the Meeting of AAUP National Conference, Washington, DC

7. Porter, D. (2012). Assessment as a subversive activity. AAUP Journal of Academic Freedom, 3, 1-28.

8. Smith, P. K. (2011). Standing strong in disturbing times: The academy's challenge. Educational Studies, 47, 215-216.

9. Suskie, L. A. (2009). Assessing student learning (second ed.). San Francisco, California: Jossey Bass Higher and Adult Education Series. 